\title{
Math Teachers' Pedagogical Practices: An Index to Students Learning Outcomes
}

\author{
Roger De Guzman Capua \\ Faculty, College of Education, \\ Ifugao State University-Potia Campus, Philippines \\ e-mail: capuaroger.coe.ifsu@ gmail.com
}

Received: 17 October 2020; Accepted: 05 March 2021; Published: 17 March 2021

To cite this article (APA): Capua, R. D. G. (2021). Math Teachers' Pedagogical Practices: An Index to Students Learning Outcomes. EDUCATUM Journal of Social Sciences, 7(1), 67-76. https://doi.org/10.37134/ejoss.vol7.1.7.2021

To link to this article: https://doi.org/10.37134/ejoss.vol7.1.7.2021

\begin{abstract}
This study focused on teachers' pedagogical practices as an index to students learning outcomes. It catered to five key problems, such as assessing the students on their teacher's knowledge and delivery of the lessons, which was confirmed positively by a majority of the students-respondents. Aligned with this is on teachers' method and strategies and the ability to convert lessons into productive outcomes evidenced by the responses where the majority were positive responses. There were areas of difficulties confirmed, foremost of which were teachers' lack of focus on the nature of the problems, which responded in the follow-up interview was overcome by considering the conduct of a rigid interviews and exercises. Further surfaced were caused by difficulties students encountered, which is teachers' lack of focus on the tenor of problems under study. To cap up the study's context is an interview focusing on students' feelings and responses to the subject where the common contention was on students' demand toward the clear lesson.
\end{abstract}

Keywords: Pedagogical and instructional practices, learning outcomes, mathematical skills

\section{INTRODUCTION}

The first step towards professionalizing mathematics teachers is to pursue a high-quality education and achieve excellence in teaching mathematics. In their course content, on-the-job training, field exposure, and support structures, Teacher Education Institutions (TEIs) must provide an outstanding education to potential teacher educators and not compromise for any less [1]. To be successful secondary mathematics educators, teachers must demonstrate major mathematics principles, methods, algorithms, links, and frameworks within and between mathematical material fields as stipulated by the National Council of Mathematics Teachers[2].

The content and manner in which mathematics is presented as defined by the National Council Teachers of Mathematics (NCTM) resulted from the academic structure. Compared to earlier teaching mathematics approaches, which appear to depend on the presumption that students increase awareness and skills by understanding the explanations and strategies of instructors, the NCTM Standards identified that learning mathematics is an active process. It is understood that students develop their awareness through experience by participating in interactive and purposeful activities. According to standardized instruction, the word "knowing" mathematics is described as "doing" mathematics [3].

Mathematics' contribution to scientific progress and its significance in people's lives are critical elements in giving high priority to mathematics in all education programs. Teaching mathematics seeks to equip students with the mathematical skills and knowledge they need in daily life, find solutions, and 
build strategies focused on problem-solving approaches. Through education in mathematics, individuals can create opportunities to develop abstract, logical, and analytical thinking, to be competent in using mathematics to evaluate and solve problems both in school and in real-world situations. Mathematical development and achievement of students are of immense importance for these reasons. Centered on developments in the International Mathematics and Science Study [4], numerous affective variables affect student learning and achievements, student attitudes, home learning support, educational approaches, teacher characteristics, school type, and school resources.

As far as training methods are concerned, the standards emphasize problem-solving as a medium of studying mathematics rather than just using problems in practice procedures that have been learned [56]. Students work on more complicated issues that are often rooted in actual life and applications. Students are not dissuaded from using other methods instead of typical ones [7]. Standard-based teaching emphasizes what has been called the innovation of "mathematical power," which includes learning processes through understanding, reasoning, problem-solving, linking mathematical ideas, and collaborating on mathematics with others.

The widely used terms "standard-based" and "inquiry-oriented" teaching relate to the approaches suggested in this study. However, it should be remembered that using a standards-based approach to education does not prevent the use of more conventional practices, including explicit instruction. Multiple methods are required to teach several mathematical features. The vital aspect of reformoriented teaching is the promotion of teaching methods designed to promote student learning. The Standards document asserts that the conventional emphasis on facts and skills should be broadened to include conceptual understanding and involvement in several mathematical processes [8-9]. Students may acquire complex cognitive skills and strategies by engaging aggressively in training. In reformedbased mathematics instruction, lecturers and teachers are encouraged to devote more time to classroom discussion and group activities. In this type of teaching, the instructor is neither the sole source of authority nor the primary source of information. Teachers' questioning techniques often play an intricate role in the standard of education obtained by students. Teachers may encourage student reasoning by posing questions that stimulate student learning.

As proposed in this study, developing and conducting mathematics lessons takes more time from teachers than before. The teachers are responsible for providing opportunities for students to become mathematically skilled and promote a learning atmosphere that encourages students. Based on the NCTM's Principles and Standards for School Mathematics, "Teachers must know and understand deeply the mathematics they are teaching and be able to draw on that knowledge through flexibility in their teaching tasks" [10]. While the ability to articulate and solve a problem is shown by a clear understanding of certain mathematical concepts, teaching mathematics demands much more than these MATHTEDs. Teaching mathematics does not necessarily mean learning how to explain or demonstrate how to solve a problem. Teaching mathematics requires a thorough understanding of the concepts and ideas behind any single topic of mathematics that is resolved. Educators of mathematics should have a clear understanding of the material and concepts used. Teachers must not be content with learning enough mathematics but must strive for a deeper mathematical comprehension level. Teachers must not be satisfied with knowing only one or two ways to solve problems, but rather seek to consider any possible answer or approach to problems. By having a comprehensive knowledge and understanding of mathematics, teachers can best instruct students in mathematical learning. However, rather than understanding mathematics, teachers should know how to set out mathematics contents at school and break them down into practical pieces of information to be taught. To do all of this, mathematics parents can grasp why and how mathematics applies to the 'what's of it. How teachers learn mathematics is also essential since that is the expertise they carry with them when they educate students [11].

However, the role of teacher's mathematical expertise in their instruction is not clearly stated by the National Mathematics Advisory Panel [12-13]. The field needs to understand what teaching methods are related to the mathematical abilities of teachers. The results from earlier studies of the relationship between teachers' mathematical information, their teaching, and the student's area unit are varied [1415]. Previous research either examined the correlation between teacher knowledge and student 
performance in general without paying close attention to teacher education or only concentrated on the relation between teacher expertise and their practice while ignoring the implications for student outcomes[16-17].

There has been a lack of a thorough understanding of how teacher knowledge influences student learning and how teacher education mediates the impact of their knowledge on student performance [18-19]. These limitations are partially due to the tradition of collecting teachers' knowledge at a given point in time. In contrast, a longitudinal study of teachers' knowledge would lead to a more in-depth assessment of the connection between teachers' mathematical knowledge, teaching practices, and student learning.

Mathematics is one discipline disliked by many students. They find it difficult considering that it is one subject defined by many abstractions, which entails mental ability or a keen sense of logic. It is the ability to abstract and reason out situations that validate and make clear and concrete ideas that primarily exist mentally.

Further, mathematics is defined not by a single solution to a problem. It underscores several solutions in different steps but winds up in the same answer or result. This complicates the study of mathematics, and unless one has a discerning mind, may find himself trapped in a state of confusion. And this is an observation common to almost all teachers in mathematics. The result of examinations conducted is expressive of this setback, where only a few can respond viable to the problems posed for investigation. It is out of this determined setback that strengthening is an affirmative concern to develop educators' mathematical skills.

\section{Framework of the Study}

Some elements of teacher knowledge, teaching, and student learning to influence each other, and the model in Figure 1 illustrates the dynamic, interactive relationship that exists among environmental, cognitive, and personality factors. This structure is utilized to ground this research.

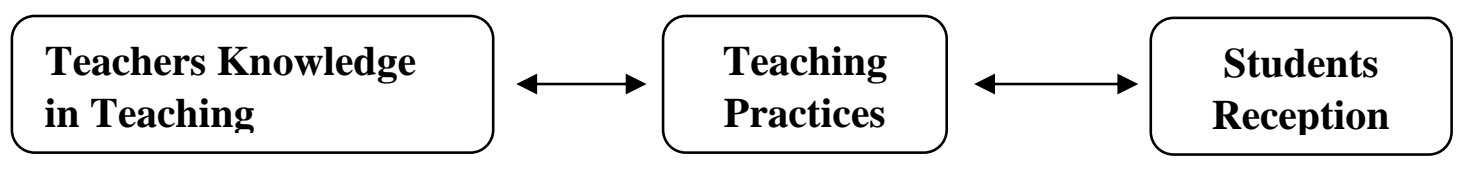

Figure 1: A framework representing the teaching as a phase between teacher knowledge and student learning

This framework illustrates how teachers' education level affects their teaching styles and students' learning.

Most findings examining the relationship between teachers' expertise and student progress were considered weak or low quality. The lack of high-quality study in this field stems from many difficulties hindering the selection of relevant studies. In order to accurately assess teachers' knowledge in teaching mathematics, different variables must be taken into account, such as the learning styles and preferences of students. Moreover, the emphasis on connecting teacher knowledge directly to student learning neglects the crucial phase of teaching, which is students' reception and learning intake (Figure 1).

This research examines what has been learned about the link involving teachers' knowledge and student understanding, addresses the difficulties in researching the link, and offers suggestions for future studies to resolve the connection between teachers' expertise and students' learning. In this study, the term knowledge for teaching mathematics uses planning, instructional practices, and reflection. It includes content knowledge and specific knowledge relevant to the teaching of mathematics. 
The researcher utilized the mathematical teaching principle introduced by [20] to endorse teaching that resulted in the most significant student learning level. The study investigates the relationship between teachers' expertise, their coaching, and their ability to influence learning.

\section{OBJECTIVE OF THE STUDY}

This study intends to surface the difficulties students have towards the mathematics subjects and to evolve solutions to mitigate if not to get rid of these difficulties. With this objective, teachers must be aware of all principles and theories, steps, and procedures to come out responsive to the call of developing mathematically inclined and logically prepared to learn to square up with complicated situations. Thus, this study investigates the teachers' mathematical knowledge role as an index of students' learning outcomes. The research queries that guided this analysis are:

1. What are the students' assessments on their teachers' knowledge in delivering lessons in Mathematics in terms of:

a. the type of strategies/methods/ approaches?

b. ability to convert lessons into learning outcomes?

2. What areas of difficulties are met by the students?

3. What are the causes behind these difficulties?

4. What is the focus of the interview conducted by math teachers to the students, and what suggestions arrived at?

\section{METHOD}

This research undertaking used the qualitative case method of study, supplemented by the descriptive method of research. The case approach was selected because it involves evaluating the areas of mathematics that were considered to be the root causes of the students' shortcomings in order to enhance their learning performance. Descriptive research was employed because it also unfolds the current situation and difficulties the students are confronted with. This study's principal aim is to gain an indepth knowledge of the interaction among the teachers' mathematical expertise to their teaching strategies. Specifically, the researcher checked whether the teacher's expertise and instructional strategies relate using qualitative data.

This research tools place at the Ifugao State University (IFSU) - Potia Campus. The Twelve Bachelor of Secondary Education majoring in Mathematics Students and were enrolled in Math 119 (Differential Calculus) were the primary data sources. The procedure entails a reciprocal exchange of views from the needed procedures, instructional techniques, and analysis served as the anchor to remediation on whatever setbacks may occur in the teaching-learning process.

One set of instrument was utilized for the face to face interview with the students. The conduct of the interview with students was a typical qualitative framework of semi-structured and open-ended in nature. It was arranged schedule-situation where series of questions comprised the context of the interview. This interview aims to examine students' impressions of the implementation, the tasks performed, what it means to be a student inside the classroom, and classroom management perspectives. A letter was given to each student participant before the interview to inform the study's nature and purpose. Both the participants and the researcher signed informed consent documents at the outset of the study.

To evaluate the transcripts, we categorized and discussed common patterns and marked gaps in what the students think teachers should do. Mainly, transcripts were originally coded in such a context as to extract distinguishing 'markers,' textual and discursive "markers," of what defines - the students' 
viewpoint - of "good" instructor and "good" teaching method. Such approaches include, for instance, student reference to inclusive teacher roles, student-centered teaching methods, fair teacher strategies, enjoyable and active learning experiences and possibilities, and structured learning events and opportunities. These identifiers were defined, classified, and then used as examples to validate various teaching modes.

\section{RESULTS AND DISCUSSION}

The qualitative research showed that instructors' mathematical knowledge for teaching (MKT) is related to teachers' instructional practices, but the assessment did not help understand why this association occurred. In prior studies, beliefs were shown to be important in teaching strategies [21]. This research helps identify which of the instructional practices are associated with teachers' mathematical awareness and which ones are associated with students' achievement.

Analyses of longitudinal survey data presented in the literature found that improvements in teachers' awareness of mathematics corresponded to changes in teachers' practices. The results show that teachers' mathematical knowledge for teaching (MKT) is closely linked to (a) how teachers planned their lessons, (b) how friendly the atmosphere they built for their students, (c) how they introduced their lessons, and (d) how clear they were in communicating critical mathematical ideas to their students.

This paper briefly presents the findings that surfaced in response to the problems under study. There were five (5) key questions covered in this study, where the responses composed the presentation's gist.

There were three (3) males and nine (9) females' respondent of this study. The problems and outcomes arrived at were sequenced in the order of the statement of the problem. The analysis considers only the dominant and the least considered among the responses of the students. Only the dominant and least responses were considered because it fits the answer needed in the study.

The findings are as follows, rated only in ranking considering the dominant and the least responded questions.

On question number 1 - on students' assessment on the teaching of Mathematics, there are 8 dominant responses saying "Lesson presentation, particularly on problem-solving, is through modular activities", and 3 less responses also says that "Students are asked to work out problems individually with less concern for group work".

On question number 2 - on the ability to convert lessons into learning outcomes, 7 respondents say that "Teachers must be concerned with steps and procedures and aline such steps and procedures toward learning outcomes. Written activities reinforced by oral presentation and recitation", while 4 respondents answered that "Teachers letting students work out by themselves and discover solutions to their difficulties".

On question number 3 - on areas of difficulties, the following response were gathered "Complicated lesson presentation, which breeds confusion and weak comprehension", and "Teachers lack explanation, which leaves students flat-footed on procedures, principles, and steps". These responses were gathered from the 6 dominant respondents and 3 least respondents respectively.

On question number 4 - on causes of difficulties, 6 respondents answered that "Teachers lack focus on the problem's tenor, thus creating an inability to apply appropriate procedure and solution", while other respondents also say that "Student's a weak sense of comprehension, thus causing an inability to decipher what is intended to be responded to". 
On question number 5 - on the focus of the interview conducted, according to the 7 dominant respondents "The focus was on students' feelings and responses to the subject and the mode of lesson presentation- the - response was on students' demand toward clear lesson presentation with examples or practical presentation. Through this, they are led to better imbibe with the lesson", while the 4 least respondents say that "The interview focuses only on weak points, which is an imbalanced approach. The feasible manner is also to highlight the strong points and merits in learning the subject".

Based on the five (5) questions by the respondents showed a positive relationship among the teachers' mathematical skills and their teaching improvement. Moreover, longitudinal and cross-sectional studies of teachers' strategies showed that the result of the gain of mathematical knowledge had quite a similar effect on teachers' strategies toward more teaching. While when looking at teachers' techniques at some time points that there seemed to be a poor association, or no relationship, amongst teachers' knowledge of mathematics and their use of teaching.

The teachers' use of mathematics changed according to their teaching knowledge. Teachers who demonstrated insufficient mathematical knowledge failed to demonstrate to students their mathematical skills. The instructor listened to the students discuss their thoughts but did not allow any discussions that included advanced mathematical concepts. Teachers with poor mathematical abilities didn't let students explore the concepts or justify them to others. However, teachers with more significant mathematics expertise were more capable of generating mathematical debate and more capable of evaluating students' responses.

This research has many applications, including teacher education, professional development, educational policies, and research.

This study provides researchers and teachers with valuable details regarding which elements of instructional activities are associated with teacher awareness and which ones are related to teacher perception. The fact that teachers who had more significant improvements in MKT appeared to shift toward more approaches and may indicate that such experience may be connected, in substantial ways, to the method taught. The level of mathematical knowledge among teachers was related to the quality of math lessons. However, it was a small sample size of twelve college students. Additional research is required to investigate whether the same relationships exist in other tertiary mathematics teachers and whether similar relationships exist for secondary math teachers. In order to stay current, practical and efficient, they can upgrade their pedagogical expertise and skills to help students learn the essential $21^{\text {st }}$ century skills required for sustainable growth [22].

The results of this study provide insight into the instructional methods teachers use and which are linked to their approaches. The study indicates that teachers' methods correlate with the extent to which the teachers plan the lesson, the activities and tasks they choose, and the degree to which they create a mathematically robust environment. Since the teacher's styles were documented once in this study, research capturing shifts in teachers' styles and knowledge is required to explore further how styles and knowledge interact and influence teaching practices over time.

The study also advises educators on what practices professional development designers can use to better train teachers and improve their MKT. Also, they reported being more comfortable in teaching previously difficult concepts. Courses that include both mathematical pedagogies and concepts may be valuable for teachers' in-service development. As a result of the teachers' intense mathematical ability for teaching more in a content/pedagogy hybrid course in addition to a mathematics course [23], professional development designers and educators might consider developing more hybrid courses.

This paper focuses on the interactions between teachers' approaches and students' mathematical skills and how they affect how teachers teach math. Teachers without a commitment to a standard-based practice made lesser changes to their teaching practices. Teacher education programs must focus on educating teachers on how to teach math and math teachers how to instruct effectively. According to this study, educators may not see standards-based teaching the same way that teacher educators do. 
Teachers might think that asking "how" and "why" questions about content is enough to promote student learning. Educators should address this assumption and find ways to help teachers use student responses to understand their situation in education better. Qualitative interpretations of the data suggested that teachers expressed issues in selecting appropriate math exercises for their students. The study found that teachers with good mathematical skills were not proficient in choosing mathematical problems rich with mathematical use. In teacher education systems, particular attention should be provided to issues and events that teachers should include in their lessons. Teachers should be mindful that math is meant to be enjoyable and make math fun through activities. Students who study using contextual approaches have stronger problem solving capabilities than students who learn both as a whole and focused on initial skills using traditional approaches [24].

The study concludes that it is not easy to detect the impact teachers have on their students learning with standardized tests. Consequently, the content could not comprehensively cover all the educational activities required by the state. Therefore, educational development planners should consider using alternative tests to decide whether students gained more experience in particular subject areas.

Based on past studies [25], this paper proposes that students are charged with work collaboratively and communicating and illustrating their ideas to enhance student learning. Research does not indicate that teaching students correctly and pressing students to probe their thought is linked to standardized test scores. Assessment exams mandated by the state are performed in the middle of the course. Researchers also found that teachers have been trapped between conventional teaching methods and modern classroom technologies [26-27]. Nonetheless, the study indicates that teachers use state test scores as a benchmark when assessing various teaching methods.

Another possible consequence is educators' appraisal in terms of the importance of student test scores, thus echoing the issues associated with not correctly accounting for prevailing student-related variables in teacher assessments [28-29]. This research also indicates that the student population in teacher's classrooms hides the teacher's overall efficacy. This paper demonstrates that the variation in teachers' performance [30] is linked not only to "noise" in student evaluations and to student demographics as historically assessed but also variations in the "personalities" of student populations assigned to the teachers. While one would expect a professional instructor to establish a favorable environment for learning within the class, this study's findings show that it depends on the students and educators. Without controlling students' characteristics, desires, motivation, and previous experiences, conventional teacher effectiveness assessments cannot reliably classify teachers with the most successful teaching skills. Utilizing student paths to some degree may influence students' associated factors. However, considering that current student trajectory models do not consider individual student characteristics (e.g., Education Value Assessment System (EVAAS), more advanced student path models are required for more reliable teacher performance measurements.

\section{CONCLUSION}

As examined in this study, there has been an attempt to determine the relationship among teachers' KTM and students' learning in the mathematics education research field. Current studies have contributed a great deal to our comprehension of this relationship. However, it must be noted that teacher's knowledge and students' comprehension is not always explicitly influenced by the middle level, "teaching," where teachers' KTMs are evaluated, and the student's learning is measured. Studies reveal that critical factors in effective teaching include teachers' beliefs and assumptions about students' understanding than their KTM, and some of the aspects in effective teaching (e.g., teachers' mathematical language usage and students response.) are not strongly linked to teachers' MKT ratings. Various studies have shown that the educational environment has consequences for students' learning of the concepts. The lack of precise measurement of KTM, which varies over time, also makes it difficult to research this relationship. Recent studies used enhanced research methods with welldesigned evaluations for teachers' in MKT and monitored other factors influencing teachers' 
instructive practice and students' accomplishments. However, this study fails to (a) provide an overview of how teacher awareness evolves or (b) how teachers can use the results to enhance their teaching practices.

The findings were the dominant response outweighed the least are expressed and evidence of progressive students learning and interest in the subject mathematics. There were problems encountered, but these were minimal, hence the recommendation for teachers to make a more precise, exhaustive, and clear presentation of matters to be learned as an imperative factor.

Further, for a better inculcation of the lesson to students, teachers should also be primarily concerned with the students' comprehensive ability. After all, it has been said that comprehension is the basis of knowing what is and what is not.

Finally, besides watching the consequences of combined instructional practices, researchers may examine the issue of implementing varied instructional practices. Recent work by [31] focuses on the relatively simple implementation of various curricula that inflict combinations of practices. It might be instructive to more this line of research, together with research on the relative simplicity of implementing specific instructional practices. For instance, our findings suggest that increasing the quantity of math instructional time in a large or whole-class setting is expounded to increased student achievement. Creating this instructional change could be easy for several academe. However, increasing the frequency with that students facilitate each other perceive mathematics ideas or proceduresanother practice positively associated with student achievement - could be more difficult for few teachers (particularly in some classrooms), in this it'd need a higher level of pedagogic knowledge content quitter merely restructuring the class for a lot of whole-class activities. Experiments on these problems or issues would create a substantive contribution to both research and practice.

\section{RECOMMENDATIONS}

As a logical offshoot of the findings surfaced, the following are highly recommended: (1) Teachers should concretize lessons by presenting examples. (2) Problems should not be let alone to stay as problems but must be given the proper solution, and interventions or solutions must be presented in a sequential method. (3) Group activities should be strengthened as it through the communion of several ideas that learning and teaching are enlarged. (4) Teacher-student relationships should be an amicable one, where each feels at ease with each other, which serves as a viable index towards collaborative teaching and learning to determine the causes of difficulties to come up with the needed measures of solutions. (5) Teachers should focus on students understanding and weaknesses for a clear and simplified presentation of problems. (6) More researches, along with this, should be undertaken to serve as references for future researchers.

\section{ACKNOWLEDGEMENT}

Sincerest Gratitude is given to the Ifugao State University-Potia Campus family for giving and motivating the researcher to pursue this study. Gratitude is also indebted to the Dean, Department Chair, and faculty of the College of Education. Above all, to the Almighty God for the wisdom, knowledge, guidance, and perseverance in doing this research work. 


\section{REFERENCES}

[1] Patahuddin, S. M., Beddu, U. H., \& Ramful, A. (2015). Affordances and constraints by mathematical tasks, questions, prompts, and teacher actions: Insights from a lesson on fractions. In The 7th ICMI-East Asia Regional Conference on Mathematics Education: In pursuit of quality mathematics education for all (pp. 579-586). Philippine Council of Mathematics Teachers Educators (MATHTED, Inc.

[2] Wong, K. Y. (2015). Effective mathematics lessons through an eclectic Singapore approach: Yearbook 2015, Association of Mathematics Educators. World Scientific.

[3] Stein, M. K., Silver, E. A., \& Smith, M. S. (2013). Mathematics reform and teacher development: A community of practice perspective. In Thinking practices in mathematics and science learning (pp. 2762). Routledge.

[4] Mullis, I. V., Martin, M. O., Foy, P., \& Arora, A. (2012). TIMSS 2011 international results in mathematics (pp. 139-171). Chestnut Hill, MA: TIMSS \& PIRLS International Study Center.

[5] Schoenfeld, A. (2009). Learning to think mathematically: Problem-solving, metacognition, and sense-making in mathematics. Colección Digital Eudoxus, (7).

[6] Miller, S. P., \& Hudson, P. J. (2007). Using evidence-based practices to build mathematics competence related to conceptual, procedural, and declarative knowledge. Learning Disabilities Research \& Practice, 22(1), 47-57.

[7] Sithole, A., Chiyaka, E. T., McCarthy, P., Mupinga, D. M., Bucklein, B. K., \& Kibirige, J. (2017). Student Attraction, Persistence, and Retention in STEM Programs: Successes and Continuing Challenges. Higher Education Studies, 7(1), 46-59.

[8] Hiebert, J., \& Grouws, D. A. (2007). The effects of classroom mathematics teaching on students' learning. Second handbook of research on mathematics teaching and learning, 1, 371-404.

[9] Clements, D. H., Agodini, R., \& Harris, B. (2013). Instructional Practices and Student Math Achievement: Correlations from a Study of Math Curricula. NCEE Evaluation Brief. NCEE, 2013-4020. National Center for Education Evaluation and Regional Assistance.

[10] Ferrini-Mundy, J., Floden, R., McCrory, R., Burrill, G., \& Sandow, D. (2005). Knowledge for teaching school algebra: Challenges in developing an analytic framework. American Education Research Association. Montreal, Quebec, Canada.

[11] Ball, D. L., Hill, H. C., \& Bass, H. (2005). Knowing mathematics for teaching: Who knows mathematics well enough to teach third grade, and how can we decide?.

[12] Martin, D. B. (2008). E (race)ing race from a national conversation on mathematics teaching and learning: The national mathematics advisory panel as white institutional space. The Mathematics Enthusiast, 5(2), 387-398.

[13] Booth, J. L., \& Newton, K. J. (2012). Fractions: Could they really be the gatekeeper's doorman?. Contemporary Educational Psychology, 37(4), 247-253.

[14] Cross, D. I. (2009). Alignment, cohesion, and change: Examining mathematics teachers' belief structures and their influence on instructional practices. Journal of Mathematics Teacher Education, 12(5), 325-346.

[15] Hill, H. C. (2010). The nature and predictors of elementary teachers' mathematical knowledge for teaching. Journal for Research in Mathematics Education, 513-545.

[16] Steele, M. D., \& Hillen, A. F. (2012). The content-focused methods course: A model for integrating pedagogy and mathematics content. Mathematics Teacher Educator, 1(1), 53-70.

[17] Chedister, M. (2013). The effects of a professional development program on teachers' beliefs and teaching of mathematical proofs (Doctoral dissertation, Boston University).

[18] Graeber, A., \& Tirosh, D. (2008). Pedagogical content knowledge: Useful concept or elusive notion. In International Handbook of Mathematics Teacher Education: Volume 1 (pp. 115-132). Brill Sense.

[19] Depaepe, F., Verschaffel, L., \& Kelchtermans, G. (2013). Pedagogical content knowledge: A systematic review of the way in which the concept has pervaded mathematics educational research. Teaching and teacher education, 34, 12-25.

[20] Ball, D. L., Thames, M. H., \& Phelps, G. (2008). Content knowledge for teaching: What makes it special. Journal of teacher education, 59(5), 389-407.

[21] Purnomo, Y. W., Suryadi, D., \& Darwish, S. (2017). Examining pre-service elementary school teacher beliefs and instructional practices in mathematics class. International Electronic Journal of Elementary Education, 8(4), 629-642.

[22] OVIAWE, J. I., \& Uddin, P. S. O. (2020). Impact of geometrical construction on students' creativity skills for sustainable development. EDUCATUM Journal of Science, Mathematics and Technology, 7(2), 4049. https://doi.org/10.37134/ejsmt.vol7.2.5.2020

[23] Copur-Gencturk, Y., \& Lubienski, S. T. (2013). Measuring mathematical knowledge for teaching: a longitudinal study using two measures. Journal of Mathematics Teacher Education, 16(3), 211-236. 
[24] Yerizon, Y., Ahda, Y., \& Amsari, D. (2019). The influence of contextual approach to students' problem solving ability of Class IX of SMP Negeri 1 Bayang. EDUCATUM Journal of Science, Mathematics and Technology, 6(2), 1-8. https://doi.org/10.37134/ejsmt.vol6.2.1.2019

[25] Zangori, L., Vo, T., Forbes, C. T., \& Schwarz, C. V. (2017). Supporting 3rd-grade students' model-based explanations about groundwater: A quasi-experimental study of a curricular intervention. International Journal of Science Education, 39(11), 1421-1442.

[26] Hiebert, J., \& Grouws, D. A. (2007). The effects of classroom mathematics teaching on students' learning. Second handbook of research on mathematics teaching and learning, 1, 371-404.

[27] Lester, F. K. (Ed.). (2007). Second handbook of research on mathematics teaching and learning: A project of the National Council of Teachers of Mathematics. IAP.

[28] Amrein-Beardsley, A. (2008). Methodological concerns about the education value-added assessment system. Educational researcher, 37(2), 65-75.

[29] Charalambous, C. Y. (2010). Mathematical knowledge for teaching and task unfolding: An exploratory study. The Elementary School Journal, 110(3), 247-278.

[30] Goldhaber, D., \& Hansen, M. (2013). Is it just a bad class? Assessing the long-term stability of estimated teacher performance. Economica, 80(319), 589-612.

[31] Abdirad, H., \& Dossick, C. S. (2016). BIM curriculum design in architecture, engineering, and construction education: a systematic review. Journal of Information Technology in Construction (ITcon), 21(17), 250271. 